\title{
Influence of Binder Types and Temperatures on the Mechanical Properties and Microstructure of Cemented Paste Backfill
}

\author{
Zhaowen Du $\mathbb{D}^{1,2}$ Shaojie Chen $\mathbb{D}^{1,2}$ Sheng Wang, ${ }^{1,2}$ Rui Liu, ${ }^{1,2}$ Dehao Yao, ${ }^{1,2}$ \\ and Hani S. Mitri ${ }^{3}$ \\ ${ }^{1}$ College of Energy and Mining Engineering, Shandong University of Science and Technology, Qingdao 266590, China \\ ${ }^{2}$ State Key Laboratory Breeding Base for Mining Disaster Prevention and Control, \\ Shandong University of Science and Technology, Qingdao 266590, China \\ ${ }^{3}$ Department of Mining and Materials Engineering, McGill University, Montreal, Canada
}

Correspondence should be addressed to Shaojie Chen; csjwyb@163.com

Received 23 December 2020; Revised 29 January 2021; Accepted 25 February 2021; Published 8 March 2021

Academic Editor: Lijie Guo

Copyright $\odot 2021$ Zhaowen Du et al. This is an open access article distributed under the Creative Commons Attribution License, which permits unrestricted use, distribution, and reproduction in any medium, provided the original work is properly cited.

In order to study the influence of burial depth or fire on the core area of cemented paste backfill (CPB), the experiment of CPB with different types of binder and temperature was carried out. Three types of binders, red mud (RM), Portland cement (PC), and slag cement (SC), are used and tested at $20^{\circ} \mathrm{C}, 40^{\circ} \mathrm{C}, 60^{\circ} \mathrm{C}$, and $80^{\circ} \mathrm{C}$. The macroperformance and microstructural evolution of $\mathrm{CPB}$ are analyzed using slump, uniaxial compressive strength (UCS), X-ray diffraction, and scanning electron microscopy (SEM). The results show that the coupled effects of binder type and temperature have a significant impact on the macroscopic performance and microstructural evolution of $\mathrm{CPB}$. The $\mathrm{CPB}$ slump prepared with three types of binder meets the production requirement of the mine. Regardless of curing temperature and curing time, the uniaxial compressive strength of CPB samples with PC and SC is much higher than that of CPB samples with red mud. When cured for 12 hours, the uniaxial compressive strength of CPB samples containing PC and SC increases first, then decreases, and finally increases again with the increase of temperature. However, with the increase of temperature, the uniaxial compressive strength of $\mathrm{CPB}$ samples containing RM only increases first and then decreases. When the curing temperature is less than $40^{\circ} \mathrm{C}$, the main reason for the increase in UCS was attributed to the fact that the temperature increase accelerates the hydration reaction and improves the density of the sample. When the curing temperature is $60^{\circ} \mathrm{C}$, the main reason for the decrease in UCS is the formation of the expansive ettringite (AFt) which destroys the internal spatial structure of the sample. When the curing temperature is $80^{\circ} \mathrm{C}$, the UCS increases again due to the fact that such high temperature can destroy the crystal structure of AFt and harden the hydration product C-S-H gel.

\section{Introduction}

Cemented paste backfill (CPB) is an environmentally friendly filling material that has attracted increasing attention and has been extensively used by mining operations [1-3]. CPB is essentially made from solid granular waste produced by operations such as milling and coal separation. The benefits of $\mathrm{CPB}$ are many including better underground mine stability, control of surface subsidence, and enhanced ore recovery. By using $\mathrm{CPB}$, it is possible to mine under surface infrastructure such as buildings and railways and mine under water [4-6]. $\mathrm{CPB}$ used in coal mines is mainly made of binder, fly ash, and coal gangue; its solid content is in the range of $70 \%$ to $85 \%$.
As one of the components of $\mathrm{CPB}$, binder mainly plays the role of cementation. When the binder is in contact with water, it will undergo hydration reaction and generate hydration products to provide strength for $\mathrm{CPB}$. The cost of binder for coal mines accounts for $90 \%$ of the total cost of $\mathrm{CPB}$ filling materials (for example, the Xinhe Coal Mine in the Shandong Province in China). Portland cement (PC) has been traditionally used as a binder in proportions that commonly range from $2 \%$ to $7 \%$ by total weight $[7,8]$. However, different types of binders have different prices and cementitious effects. Therefore, it is of great significance to study the influence of different types of binders on the performance of CPB. With the depletion of shallow coal 
resources in China, the depth of coal mining is increasing every year, and the geothermal problem is becoming increasingly serious. During the process of paste backfill in the mine, the posterior part of the working face is in a completely closed state with poor ventilation. Combined with the influences of rock temperature, air compression and expansion, hydration reaction, and heat generation, the temperature behind the working face can be significantly hot. Therefore, it is necessary to conduct experimental research on the thermal stability of CPB.

In recent decades, many scholars have conducted extensive research on the factors influencing the performance of CPB. Wu et al. [9] investigated the effects of three types of binders on $\mathrm{CPB}$, and the results showed that these types of binders had a significant impact on the coagulation performance and compressive strength. Ercikdi et al. [10] investigated the effects of OPC, PCC, and SRC, on the mechanical properties and microstructure of $\mathrm{CPB}$. The results showed that the mechanical properties of CPB were closely related to sulphide-rich tailings. Sun et al. [11] studied the influences of different silica fume proportions as binders on $\mathrm{CPB}$ properties, and the results showed that the UCS of CPB samples are largest when the silica fume proportion is $5 \%$. Xu et al. [12] studied the effect of the type of binder on UCS. The results showed that the slag cement (SC) has more advantages than PC and SC with 5 wt \% $\mathrm{NaOH}$. Yilmaz et al. [13] studied the effect of curing time and content of different types of binders on the characteristics of CPB samples based on the use of an improved experimental apparatus. The results showed that the effects of different binder types on the mechanical properties of CPB mainly depend on the different consolidation behaviors of different binder types.

Previous studies showed that the type of binder has a significant effect on the performance of CPB. However, there are a few studies on the effect of ambient temperature as an influencing factor on the performance of CPB. In addition, some studies only investigated the effect of a single factor on CPB performance $[14,15]$. There are no studies on the coupled effects of binder type and temperature on strength development and microstructural evolution of CPB.

Therefore, this study investigates the coupled effects of binder type and temperature on strength development and microstructural evolution of CPB. The purpose of this experimental research is to examine (a) whether the $\mathrm{CPB}$ containing three types of binder can meet the engineering requirements of paste slump, (b) the influence of binder type and temperature on UCS properties, and (c) the microstructural evolution of $\mathrm{CPB}$.

\section{Materials and Methods}

\subsection{Materials}

2.1.1. Binders. Three types of binders were used in this experiment. These binders are red mud (RM), PC, and SC, as shown in Figure 1. The RM used in this experiment was produced by the Bayer process at the Haitao Aluminum Mine in Henan Province, with a density of $3.01 \mathrm{~g} / \mathrm{cm}^{3}$ and a specific surface area of $0.48 \mathrm{~m}^{2} / \mathrm{g}$. The PC and SC binders were produced by the Yishui Cement Plant in the Shandong Province. Their densities are $3.07 \mathrm{~g} / \mathrm{cm}^{3}$ and $3.1 \mathrm{~g} / \mathrm{cm}^{3}$, respectively, and their specific surface areas are $0.36 \mathrm{~m}^{2} / \mathrm{g}$ and $0.39 \mathrm{~m}^{2} / \mathrm{g}$, respectively. Their main chemical compositions are shown in Table 1.

2.1.2. Fly Ash. The fly ash used in the experiment is grade II fly ash from the Huangdao Power Plant in the Qingdao city in the Shandong Province, with a density of $2.15 \mathrm{~g} / \mathrm{cm}^{3}$ and a specific surface area of $0.98 \mathrm{~m}^{2} / \mathrm{g}$. And its appearance is light gray. Its main chemical composition is shown in Table 2 .

2.1.3. Coal Gangue. The gangue selected in this experiment comes from solid waste produced in the process of roadway excavation, coal mining, and separation in the Daizhuang Coal Mine at the Zibo Mining Group in the Shandong Province. Its particle size is less than $25 \mathrm{~mm}$. Its chemical properties and particle size are shown in Tables 3 and 4.

2.2. Mixing Procedure and Mix Proportions. Samples used for the experiment are mainly made of RM, PC, SC, fly ash, and gangue. Considering the composition of CPB at Daizhuang Coal Mine of Zibo Mining Bureau of Shandong Province, the Bureau pointed out that when the mix ratio of the binder to fly ash and gangue is $1: 4: 6$, the product performance was optimal $[16,17]$. In the same way, three types of binders were chosen for the synthesis of samples subject to constant proportion conditions. First, the filling material was mixed and stirred according to the designed proportion. The stirred $\mathrm{CPB}$ was then injected into cubic molds of $70.7 \mathrm{~mm} \times 70.7 \mathrm{~mm} \times 70.7 \mathrm{~mm}$. Once shaken and tamped, CPB samples are then placed in constant temperature and humidity chamber to cure for 28 days. After 28 days, the samples were cured at $40^{\circ} \mathrm{C}, 60^{\circ} \mathrm{C}$, and $80^{\circ} \mathrm{C}$, for 4,8 , and 12 hours, respectively.

\subsection{Testing Methods}

2.3.1. Slump Measurement. Slump is a comprehensive index used to evaluate the transportation performance of CPB in pipeline $[18,19]$. In this work, the $C P B$ slump test was conducted in accordance with the American Society for Testing and Materials (ASTM) standard C143 [20]. The upper and lower diameters of the slump cone are $100 \mathrm{~mm}$ and $200 \mathrm{~mm}$, respectively, and the height is $300 \mathrm{~mm}$. The $\mathrm{CPB}$ is poured into the cone, and a shaker is used to ensure complete filling. Once the cone is filled, excess material is removed. The cone is slowly lifted during a 5-10 second period, and the height of the sample is measured.

2.3.2. Testing of Mechanical Properties. The UCS is frequently tested to evaluate the mechanical performance of CPB. UCS tests are relatively inexpensive and can be easily incorporated into routine quality control programs in mines $[21,22]$. In the current laboratory investigation, the UCS values of CPB were determined with a Shimazu AG-X250 electric hydraulic pressure-testing machine. The test 


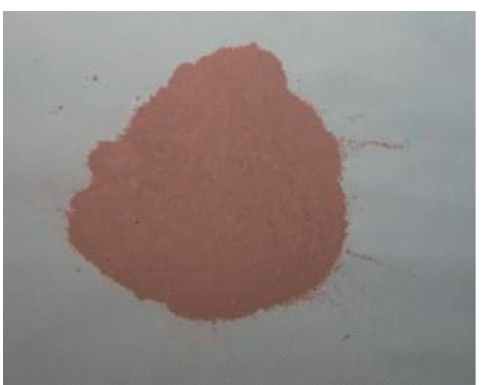

(a)

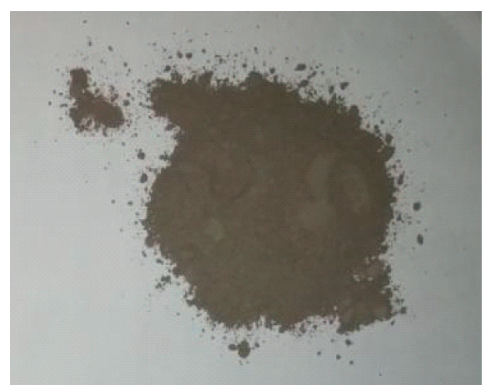

(b)

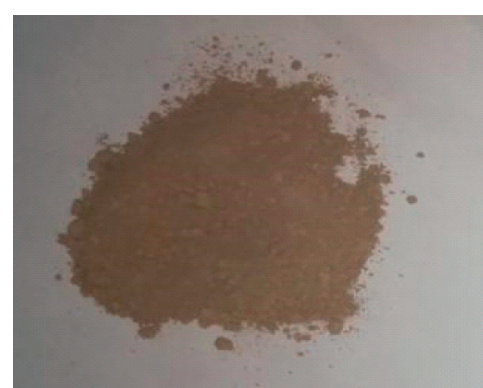

(c)

Figure 1: Three types of binders: (a) red mud, (b) Portland cement, and (c) slag cement.

TABLE 1: Main chemical constituents of binders (in \% weight).

\begin{tabular}{|c|c|c|c|c|c|}
\hline Binder & $\mathrm{CaO}$ & $\mathrm{SiO}_{2}$ & $\mathrm{Al}_{2} \mathrm{O}_{3}$ & $\mathrm{Fe}_{2} \mathrm{O}_{3}$ & $\mathrm{MgO}$ \\
\hline Red mud & 11.29 & 46.05 & 30.54 & 6.13 & 0.67 \\
\hline Portland cement & 52.41 & 29.13 & 10.38 & 1.26 & 5.31 \\
\hline Slag cement & 25.28 & 7.86 & 3.51 & 52.62 & 4.02 \\
\hline
\end{tabular}

TABle 2: Main chemical constituents of fly ash.

\begin{tabular}{lcccccc}
\hline Element unit & $\mathrm{SiO}_{2}$ & $\mathrm{Al}_{2} \mathrm{O}_{3}$ & $\mathrm{Fe}_{2} \mathrm{O}_{3}$ & $\mathrm{CaO}$ & $\mathrm{MgO}$ & Burning loss \\
\hline Weight (\%) & 53.94 & 30.91 & 2.38 & 6.53 & 0.92 & 6.34 \\
\hline
\end{tabular}

TABLE 3: Main chemical composition of gangue.

\begin{tabular}{lcccccc}
\hline Element unit & $\mathrm{CaO}$ & $\mathrm{Fe}_{2} \mathrm{O}_{3}$ & $\mathrm{Al}_{2} \mathrm{O}_{3}$ & $\mathrm{SiO}_{2}$ & $\mathrm{MgO}_{2}$ \\
\hline Weight (\%) & 2.36 & 4.3 & 18.9 & 59.1 & 1.41 & 1.89 \\
\hline
\end{tabular}

TABLE 4: Grain size grading of gangue.

\begin{tabular}{|c|c|c|c|c|c|c|}
\hline Particle size $(\mathrm{mm})$ & +10 & $10-6$ & $6-3$ & $3-1.5$ & $1.5-0$ & Total \\
\hline Weight $(\mathrm{kg})$ & 5.26 & 4.12 & 3.98 & 2.36 & 4.34 & 20.06 \\
\hline Productive rate $(\%)$ & 26.22 & 20.54 & 19.84 & 11.76 & 21.64 & 100.00 \\
\hline Accumulated on sieve (\%) & 26.22 & 46.76 & 66.60 & 78.36 & 100.00 & - \\
\hline
\end{tabular}

machine is driven by a servo-controlled motor and loaded with a double screw structure. The test machine can perform a wide variety of mechanical property tests. The precision is $\pm 0.1 \%$, the crosshead stroke measurement resolution is $0.0104 \mu \mathrm{m}$, and the effective test width is $595 \mathrm{~mm}$. The speed is $0.01 \mathrm{~mm} / \mathrm{s}$ in displacement control mode.

2.3.3. X-Ray Diffraction (XRD) Experiment. XRD was used to analyze the selected samples to identify characteristic crystalline substances generated by hydration of $\mathrm{CPB}$. The XRD analyses were performed with a Rigaku Ultima IV $\mathrm{X}$-ray diffraction device (radiation, $2 \theta=5-80^{\circ}$ ) with an operating voltage of $40 \mathrm{kV}$, an emission current of $40 \mathrm{~mA}$, and a step size of 0.02 .

First, the sample is poured into a mortar and ground into powder. Then, the powder sample is poured into the glass slot and put into the XRD diffractometer. Finally, we set the starting angle to $5^{\circ}$, the ending angle to $60^{\circ}$, and the scanning speed to $8^{\circ}$ per minute.

2.3.4. Scanning Electron Microscopy (SEM) Experiment. To observe the morphology and structure of the hydration products of $\mathrm{CPB}$ more intuitively, an APREO electron microscope (FEI, USA) was used for high- and low-vacuum scanning. Its high-vacuum resolution is $0.8 \mathrm{~nm}$ at $15 \mathrm{kV}$ and $0.8 \mathrm{~nm}$ at $1 \mathrm{kV} / 0.8 \mathrm{~nm}$ at $1 \mathrm{kV}$, and its low-vacuum resolution is $0.9 \mathrm{~nm}$ at $500 \mathrm{~V}$.

Prior to SEM observations, samples were soaked in anhydrous ethanol to prevent hydration. Then, the sample is processed into a block with a diameter of $10 \mathrm{~mm}$ and a height of $5 \mathrm{~mm}$ and sprayed with conductive metal. Then, the goldsprayed sample was placed on the scanning electron 
microscope (SEM) internal platform, and the sample was sealed and evacuated. Finally, the samples were scanned in different multiples.

\section{Results}

3.1. Effect of Binder Type on Slump Performance. Three slump tests were conducted for each type of $\mathrm{CPB}$, and the difference between the test results was less than $5 \%$. The slump test configuration is shown in Figure 2. The average slump test results are reported in Table 5 .

\subsection{Coupled Effect of Binder Type and Temperature on the UCS}

3.2.1. Four-Hour Curing Process. Figure 3 shows the UCS test results for different binder CPB types (RM, PC, and SC) after curing for 4 hours at $20^{\circ} \mathrm{C}, 40^{\circ} \mathrm{C}, 60^{\circ} \mathrm{C}$, and $80^{\circ} \mathrm{C}$. As can be seen, regardless of the curing temperature, the UCS values of CPB samples contained PC and SC are much higher than those of the CPB that contained RM. On the other hand, regardless of the type of binder, higher curing temperature leads to increase in CPB strength, with the exception of the $\mathrm{RM}$ samples at $80^{\circ} \mathrm{C}$, which gave a UCS value $0.09 \mathrm{MPa}$, the lowest strength.

3.2.2. Eight-Hour Curing Process. Figure 4 shows the UCS test results for different types of binder after curing for 8 hours at different curing temperatures. As shown in Figure 4, the UCS of the RM and PC samples exhibited the same trends; that is, the UCS increased to a peak at $60^{\circ} \mathrm{C}$ and then decreased at $80^{\circ} \mathrm{C}$ curing temperature. When the curing temperature was $60^{\circ} \mathrm{C}$, the UCS of these two types of samples reached the maximum values of $0.21 \mathrm{MPa}$ and $1.32 \mathrm{MPa}$, respectively. Compared with the curing temperature of $20^{\circ} \mathrm{C}$, the UCS of the samples cured at $60^{\circ} \mathrm{C}$, respectively, increased by $29 \%$ and $31 \%$. The UCS values of the samples containing SC after curing at $20^{\circ} \mathrm{C}, 40^{\circ} \mathrm{C}$, and $60^{\circ} \mathrm{C}$ for 8 hours exhibited minor differences, ranging from 1.69 to $1.77 \mathrm{MPa}$. However, when the curing temperature is $80^{\circ} \mathrm{C}$, the UCS of SC samples is the highest at $2.25 \mathrm{MPa}$. Compared with the curing temperature of $20^{\circ} \mathrm{C}$, the UCS of SC sample increased by $33 \%$.

3.2.3. Twelve-Hour Curing Process. Figure 5 shows the results of UCS tests for different types of binder after curing for 12 hours at $20^{\circ} \mathrm{C}, 40^{\circ} \mathrm{C}, 60^{\circ} \mathrm{C}$, and $80^{\circ} \mathrm{C}$. As shown in Figure 5 , the UCS values of the samples that contain three types of binder after curing for 12 hours at the four curing temperatures exhibit large differences. Like the results of curing after 4 and 8 hours, the UCS values of the CPB samples that contained PC and SC are much higher than those of the RM samples. When the temperature is $80^{\circ} \mathrm{C}$, the UCS value of the $\mathrm{SC}$ sample is 31.5 times that of the RM sample. At the same time, it can be observed that the SC sample shows an increasing trend followed by a decrease and a final increase at $80^{\circ} \mathrm{C}$. The UCS values of the SC samples cured at $20^{\circ} \mathrm{C}$ and $40^{\circ} \mathrm{C}$ for 12 hours are $1.69 \mathrm{MPa}$ and $1.72 \mathrm{MPa}$, respectively. However, it is worth noting that when the curing temperature is $60^{\circ} \mathrm{C}$, the UCS value of the SC sample is lowest at $1.39 \mathrm{MPa}$. In addition, the maximum UCS value of the sample at the curing temperature of $80^{\circ} \mathrm{C}$ is $2.52 \mathrm{MPa}$. As the temperature increases, the UCS values of the PC samples increase from $1.01 \mathrm{MPa}$ to $1.28 \mathrm{MPa}$, then decrease from $1.28 \mathrm{MPa}$ to $1.13 \mathrm{MPa}$, and finally increase to $1.71 \mathrm{MPa}$. At the same curing time, the UCS values of all sample types at $40^{\circ} \mathrm{C}, 60^{\circ} \mathrm{C}$, and $80^{\circ} \mathrm{C}$ are higher than those at $20^{\circ} \mathrm{C}$, with increases of $26.7 \%, 11.9 \%$, and $69.3 \%$, respectively. The UCS values of RM samples increase first and then decrease with higher temperature. The UCS values range from 0.08 to $0.21 \mathrm{MPa}$.

3.3. XRD Results. The abovementioned test results have shown that the type of binder, curing temperature, and curing time have significant influence on CPB. Furthermore, a curing time of 12 hours deems more representative than 4 and 8 hours. As can be observed from the UCS results after 12 hours of curing time, some samples showed an increase then a decrease in strength and finally exhibited increase at 80 oC. To better understand the influence of these factors, the phases of CPB samples after 12 hours of curing time were analyzed by XRD.

Figure 6 shows the XRD patterns of hydration products of $\mathrm{CPB}$ with different types of binder after curing at $20^{\circ} \mathrm{C}$ for 12 hours. As can be seen, the strongest diffraction is silica $\left(\mathrm{SiO}_{2}\right)$. The appearance of silica's diffraction peak indicates that the sample still contains numerous silica particles that do not participate in the hydration reaction. The diffraction peaks of silica in PC and SC samples are relatively weak. This indicates that more silica has participated in the hydration reaction to produce more hydration products. At the same time, the diffraction peaks of C-S-H, C-A-H, gypsum, and AFt can also be observed. The appearance of these diffraction peaks indicates that the hydration reaction occurred in the sample during the curing period and corresponding hydration products were generated. It is easy to observe that the diffraction peak of hydration products generated by the PC and SC samples is more (in number) and stronger (in intensity) than those of the RM sample. This indicates that $\mathrm{C} 3 \mathrm{~S}$ and $\mathrm{C} 3 \mathrm{~A}$ in the samples containing PC and SC participate in the hydration reaction and produce more $\mathrm{C}-\mathrm{S}-\mathrm{H}$ and calcium aluminate hydrate (C-A-H). However, the sample that yielded the largest number of peaks with the highest $\mathrm{C}-\mathrm{S}-\mathrm{H}$ and $\mathrm{AFt}$ diffraction peak intensities is the SC sample.

Figure 7 shows the XRD pattern of hydration products of $\mathrm{CPB}$ with different types of binder after curing at $40^{\circ} \mathrm{C}$ for 12 hours. It can be observed from Figure 7 that the diffraction peaks of silica, gypsum, C-S-H, and AFt still appear after the three types of $\mathrm{CPBs}$ are cured at $40^{\circ} \mathrm{C}$ for 12 hours. However, compared with Figure 6, the diffraction peaks of the hydration products of each sample are significantly enhanced, and the diffraction peak of silica is significantly decreased. The results show that the secondary hydration occurs at $40^{\circ} \mathrm{C}$ and more crystal forms of hydration products are generated. Moreover, the hydration products of the PC and SC samples (Figures $7(\mathrm{~b})$ and $7(\mathrm{c})$ ) are more than those of the RM sample (Figure $7(\mathrm{a})$ ). 


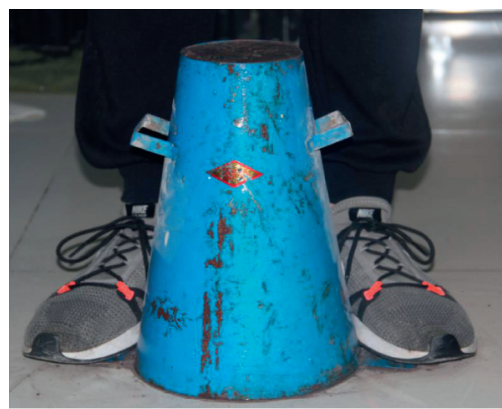

(a)

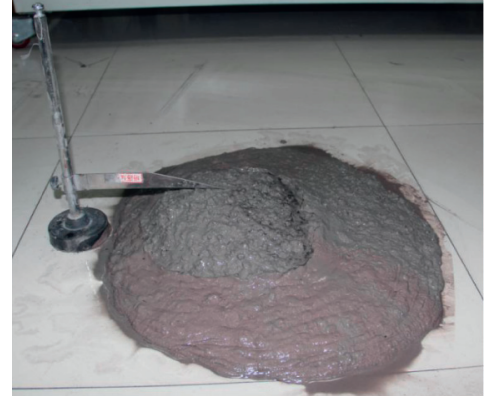

(b)

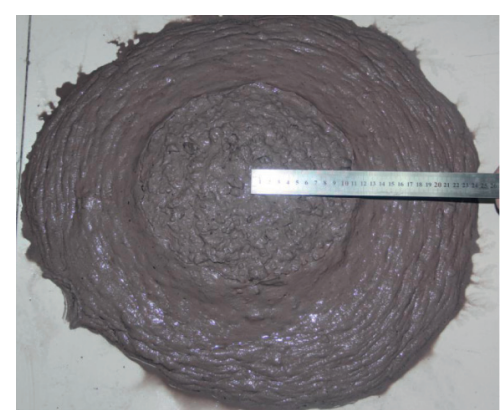

(c)

Figure 2: Slump test configuration.

TABLE 5: CPB slump test results.

\begin{tabular}{cccc}
\hline Binder & Red mud (RM) & $\begin{array}{c}\text { Portland cement } \\
(\text { PC) }\end{array}$ & Slag cement (SC) \\
\hline Slump & $22.45 \mathrm{~cm}$ & $22.55 \mathrm{~cm}$ & $25.45 \mathrm{~cm}$ \\
\hline
\end{tabular}

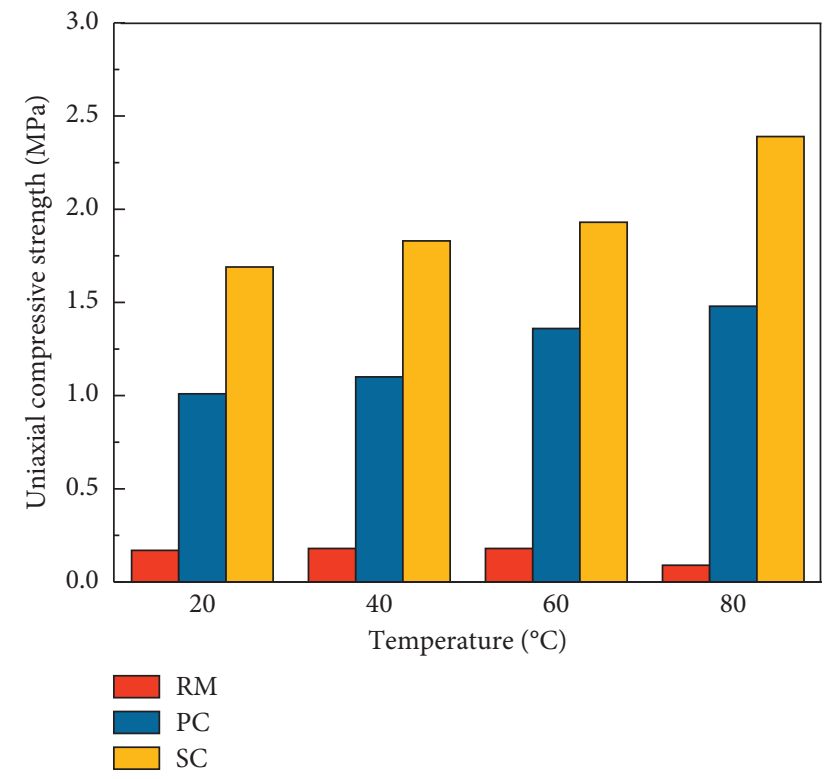

FIGURE 3: Effect of binder type and temperature on the UCS of CPB after curing for 4 hours.

Figure 8 shows the XRD pattern of hydration products of $\mathrm{CPB}$ with different types of binders after curing at $60^{\circ} \mathrm{C}$ for 12 hours. It can be observed from Figure 8 that the peak diffraction intensity is still associated with silica. In addition to silica, the diffraction peaks of $\mathrm{C}-\mathrm{S}-\mathrm{H}, \mathrm{C}-\mathrm{A}-\mathrm{H}$, and $\mathrm{AFt}$ are also relatively high. At the same time, it is obvious from Figures 8 (b) and 7 (c) that there are more hydration products, especially AFt. Compared with Figure 7, the XRD peaks of gypsum in Figures 8(b) and 8(c) are weaker, indicating that more gypsum is involved in the secondary hydration reaction to produce more $\mathrm{AFt}$.

Figure 9 shows the XRD patterns of hydration products of $\mathrm{CPB}$ with different types of binder after curing at $80^{\circ} \mathrm{C}$ for

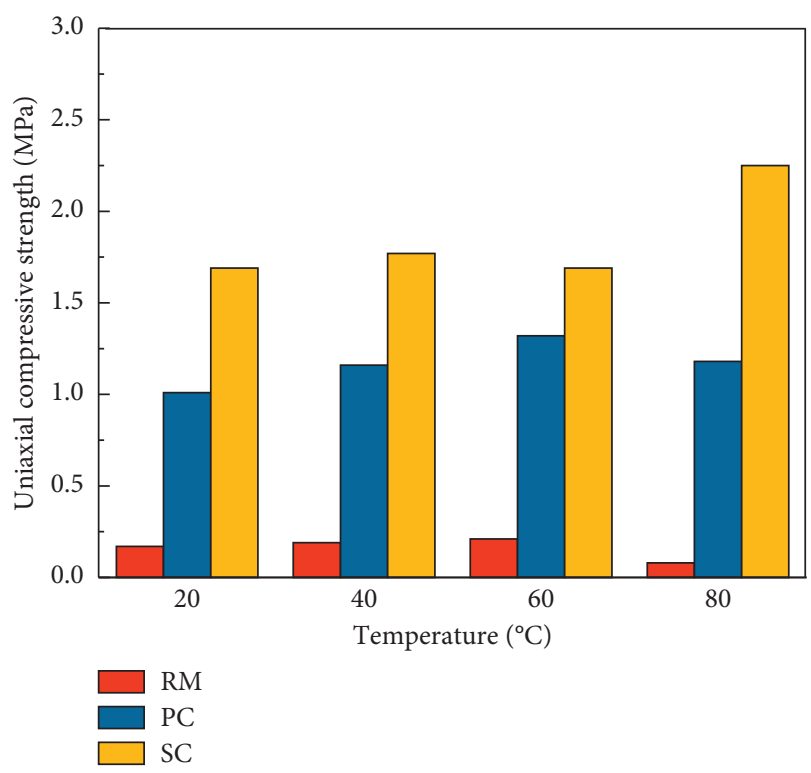

FIgURE 4: Effect of binder type and temperature on the UCS of CPB after curing for 8 hours.

12 hours. It can be observed from Figure 9 that the number of hydration products and the diffraction peak strength of the SC sample are larger than those of the PC sample. In turn, the numbers and intensities of PC peaks are larger than those of the RM sample. Figure 9(a) shows that the diffraction peak of the hydration products of the RM samples is weak, indicating that the hydration products are relatively small at $80^{\circ} \mathrm{C}$. Figures 9(b) and 9(c) show that the PC and SC samples produce more $\mathrm{C}-\mathrm{S}-\mathrm{H}$ gel after curing at $80^{\circ} \mathrm{C}$ for 12 hours. However, the AFt diffraction peaks become weaker.

3.4. SEM Results. To observe the internal microstructure of the three types of binder samples more closely, SEM tests were conducted on $\mathrm{CPB}$ samples that were cured for 12 hours.

Figure 10 shows the SEM images at a magnification of 5000 times. The SEM test results show that the microstructure of the three types of binder is different. Figure 10(a) shows that the RM sample has a single internal 


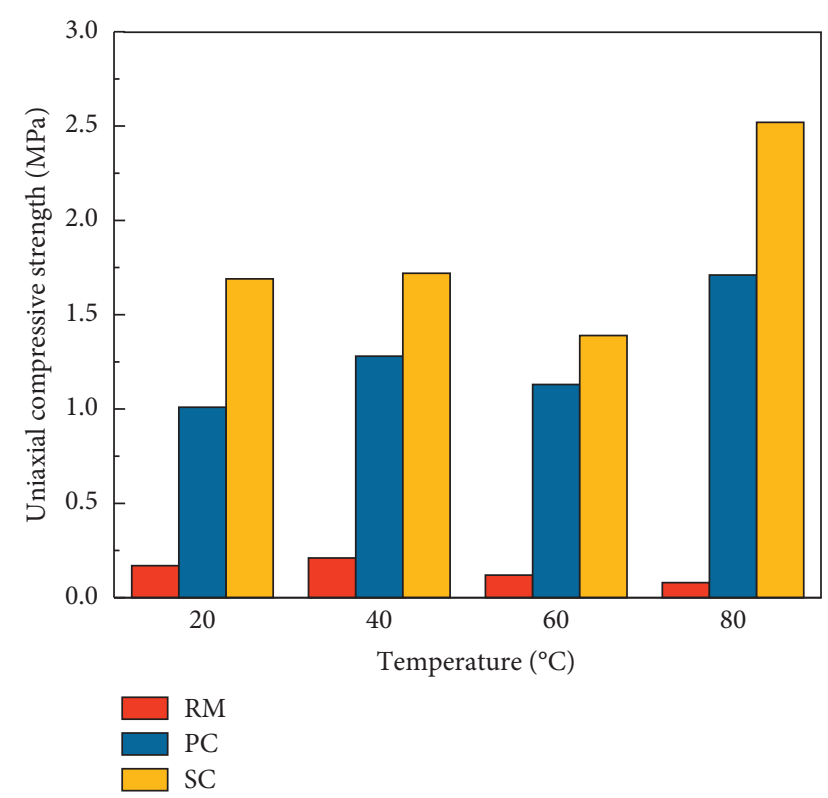

FIGURE 5: Effect of binder type and temperature on the UCS of CPB after curing for 12 hours.

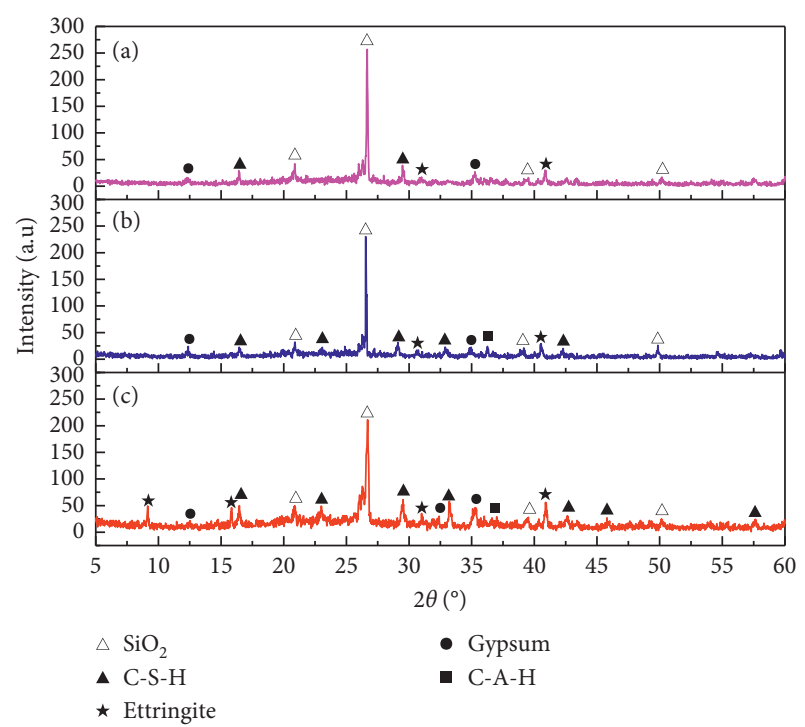

Figure 6: XRD patterns of CPB samples after curing at $20^{\circ} \mathrm{C}$ for 12 hours: (a) red mud (RM), (b) Portland cement (PC), and (c) slag cement (SC).

structure, mainly spherical fly ash. There are also a few C-S$\mathrm{H}$ gel. However, the internal structure of the PC and SC samples is more complex. Figure 10(b) displays the SEM image of the PC sample. As can be observed, there is cottonlike C-S-H gel and acicular Aft. The C-S-H gel and AFt are interlaced in the middle of the raw material. Figure 10(c) shows the SEM image of the SC sample. Overall, there are some smaller voids in the SC sample. However, outside the voids, hydration products, such as C-S-H gel, acicular, and rod-shaped AFt, are observed between the particles of the

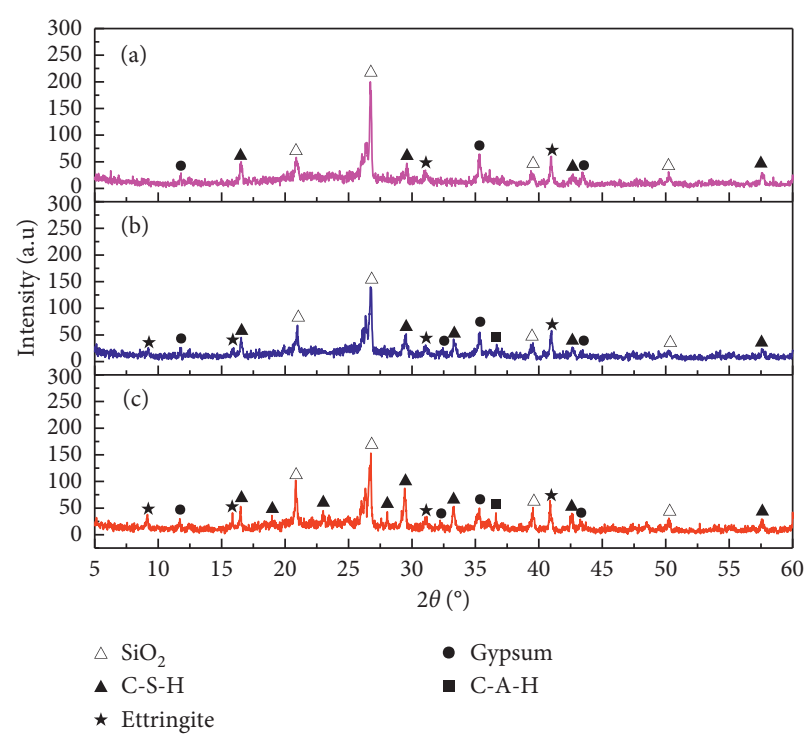

FIGURE 7: XRD patterns for $\mathrm{CPB}$ samples after curing at $40^{\circ} \mathrm{C}$ for 12 hours: (a) RM, (b) PC, and (c) SC.

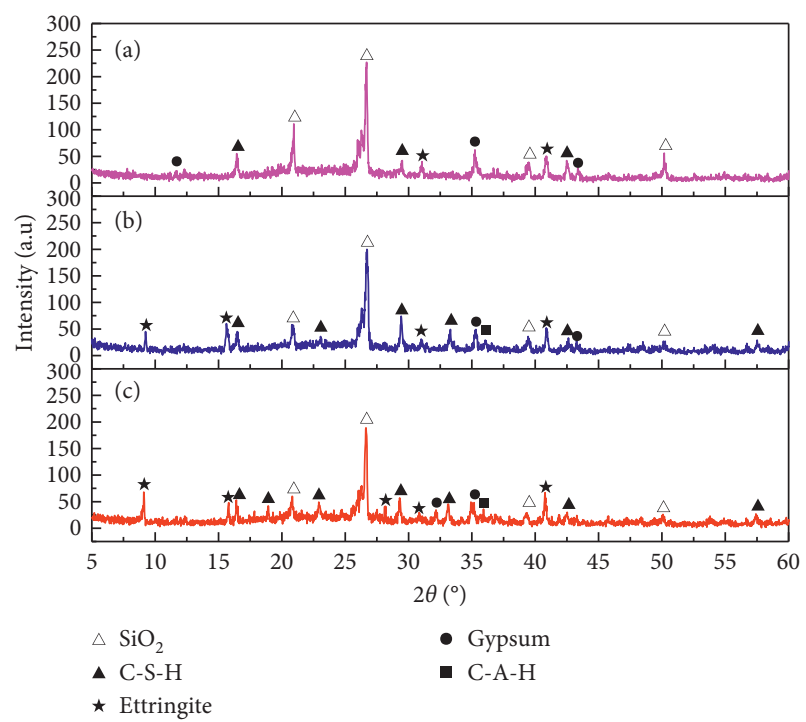

FIgURE 8: XRD patterns for CPB samples after curing at $60^{\circ} \mathrm{C}$ for 12 hours: (a) RM, (b) PC, and (c) SC.

sample. These hydration products are tightly surrounded by the raw material particles.

Figure 11 shows the SEM image magnified 5000 times after the samples of the three types of binders were cured at $60^{\circ} \mathrm{C}$ for 12 hours. Compared with Figure $10(\mathrm{a})$, the hydration products (C-S-H gel) between the particles in Figure 11(a) are increased considerably. However, it is worth noting that the PC sample in Figure 11(b) has a relatively dense internal structure with virtually no gaps. It is obvious that the hydration products are compact and evenly distributed, and the spaces between the material particles are filled in a large number of hydration products. A thick rodlike substance (AFt) is formed near and in the middle of the 


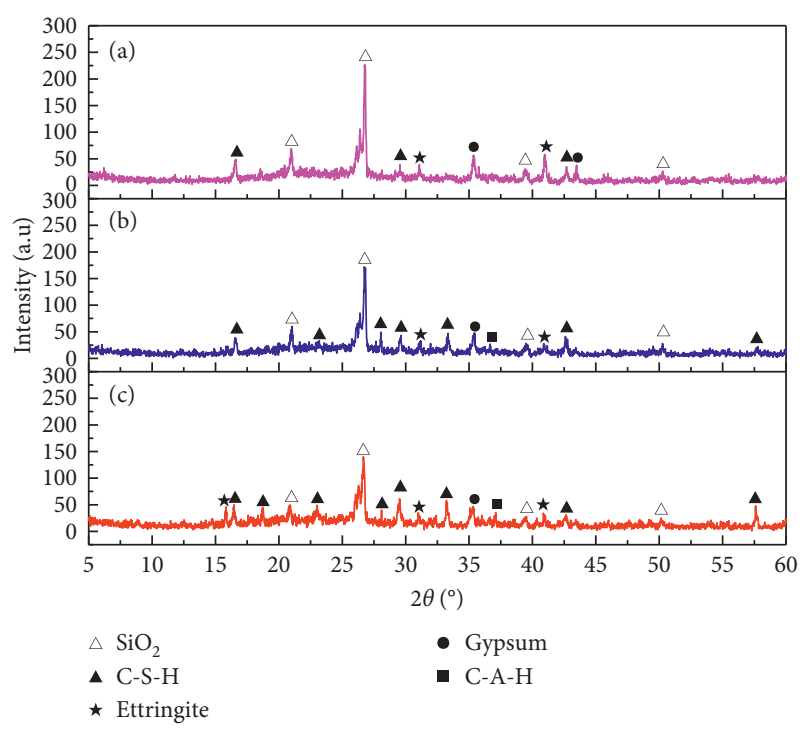

FIGURE 9: XRD patterns of CPB samples after curing at $80^{\circ} \mathrm{C}$ for 12 hours: (a) RM, (b) PC, and (c) SC.

C-S-H gel. This thick rod-like AFt breaks the C-S-H gel and is mixed tightly in the C-S-H gel. The results show that the crystal of AFt is relatively coarse and large, and there is not enough space in the sample. Figure 11(c) shows the internal structure of the sample that contains SC. It can be observed from the figure that some voids still exist inside the test piece. However, there are still cotton-like C-S-H gel and rod-like AFt crystals between the raw materials.

Figure 12 shows the SEM images magnified 5000 times after the samples of the three types of binders were cured at $80^{\circ} \mathrm{C}$ for 12 hours. At $80^{\circ} \mathrm{C}$, the hydration products can hardly be observed in the RM sample. However, it is worth noting that most of the AFt in Figures 12(b) and 12(c) has obvious damaged powdery states. In addition, in Figures 12(b) and 12(c), more cotton-like C-S-H gel has coatings with raw material particles.

\section{Discussion}

The slump test serves as a macro index for evaluating the rheological properties of $\mathrm{CPB}$ and is more easily obtained in practice. It can be clearly seen from the results in Table 5 that the slump test results of the three types of binders are not significantly different and range from $22.45 \mathrm{~cm}$ to $25.45 \mathrm{~cm}$. The results of slump test show that the $\mathrm{CPB}$ prepared by these three binders can meet the requirements of mine engineering fluidity [23].

Figures 3-5 show that the effect of curing temperature on the $\mathrm{CPB}$ strength is strongly dependent on the binder type. It is shown that the UCS values of the PC and SC samples are much higher than those of the samples that contain RM mainly because of the cementing performance of the binders in the samples. PC and SC can provide $\mathrm{CPB}$ with more raw materials for hydration reactions, such as C3S, C2S, and $\mathrm{C} 3 \mathrm{~A}$. The hydration products generated by the hydration reactions of these binders promote the filling materials to bond together, reduce the porosity in $\mathrm{CPB}$, and improve the overall UCS values of the samples [24-31]. At the same time, it can be inferred that the PC sample is more sensitive to temperature than the SC sample.

However, regardless of the curing time, the RM sample shows a trend of first increasing and then decreasing as temperature increases. Specifically, the RM sample RM yielded the lowest strength at $80^{\circ} \mathrm{C}$. The main reason for this phenomenon is the poor heat resistance of the RM sample. High temperatures are likely to hinder or destroy hydration products, thus resulting in lower UCS values. The most fundamental reason is attributed to the fact that the RM sample cannot continually provide raw materials for hydration reaction. This view is fully supported by the XRD and SEM images shown above.

Curing temperature also plays a decisive role in the UCS responses of the samples. When the samples are cured for 12 hours, the UCS values at $40^{\circ} \mathrm{C}$ are greater than those at $20^{\circ} \mathrm{C}$. The increase of UCS can be explained as the rate of temperature increase accelerates the dissolution of the clinker phase, thus accelerating the hydration process of the binder. Accordingly, hydration products (AFt and C-S-H gel) increase as a function of temperature. The formation of these hydration products is conducive to the increase of the $\mathrm{CPB}$ strength. C-S-H is the main binding phase of hardened cement. The content of C-S-H gel and AFt increases as a function of the curing temperature. With the increase of curing temperature, the precipitation of hydration products increases, thus resulting in the refinement of the void structure. As a result, the sample has a denser microstructure and a finer pore distribution that improves the strength of $\mathrm{CPB}$.

It is interesting to infer (based on In Figure 5) that the UCS of PC and SC samples decreases considerably in an environment at $60^{\circ} \mathrm{C}$. This is mainly attributed to the fact that the curing temperature of $60^{\circ} \mathrm{C}$ promotes the formation of more AFt. The AFt generation is considerably larger than the space-bearing capacity of the pores inside the sample. This has led to the expansion of the sample and the decrease of UCS. In addition, AFt itself possesses specific expansibility, and the expansion pressure leads to the decrease of the UCS $[32,33]$. AFt can break the flocculent structure of C-S$\mathrm{H}$ and reduce the integrity of C-S-H gel. The XRD pattern in Figure 8 and the SEM image in Figure 11 prove this assertion. However, the production of C-S-H gel also increases as a function of temperature. However, the overall strength of the sample decreases. The results show that AFt production, C-S-H bonding force, and the internal space of the sample have a competitive relationship at specific temperatures.

It is worth noting that the UCS values of the samples that contained PC and SC after curing at $80^{\circ} \mathrm{C}$ for 12 hours increase to $1.71 \mathrm{MPa}$ and $2.52 \mathrm{MPa}$, respectively. This is mainly attributed to the fact that the curing temperature of $80^{\circ} \mathrm{C}$ prompted the $\mathrm{PC}$ and SC samples to produce more hydration products (C-S-H gel) that are favorable to the strengths of the samples. The XRD diffraction pattern and SEM images confirm this view. It is not difficult to discern from the XRD spectra that the diffraction peak of C-S-H gel increases after curing for 12 hours at $80^{\circ} \mathrm{C}$, while the 


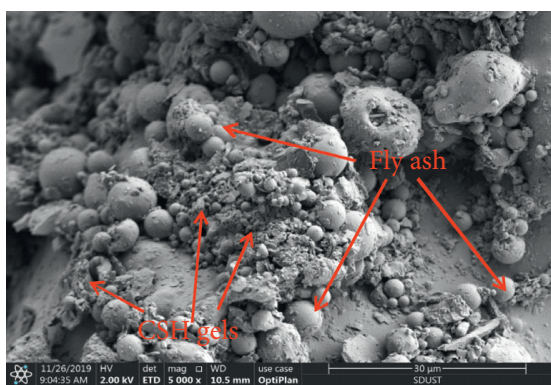

(a)

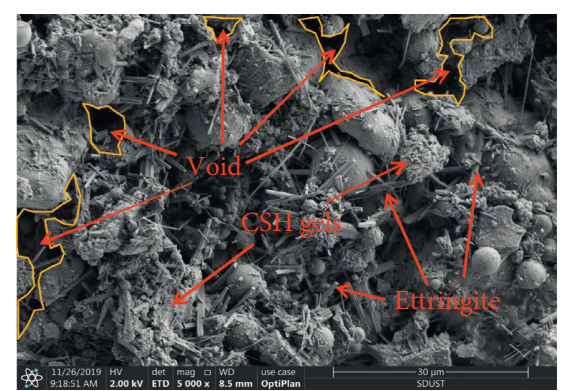

(b)

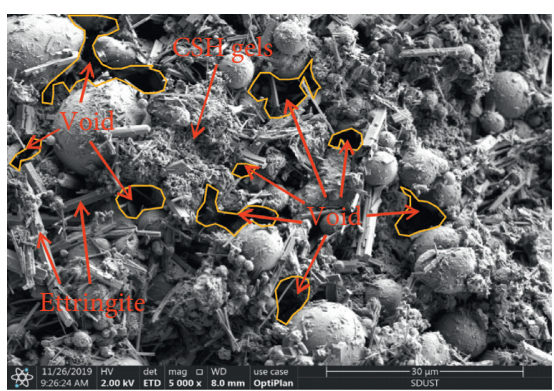

(c)

FIgURE 10: Scanning electron microscopy (SEM) images of different samples cured at $40^{\circ} \mathrm{C}$ for 12 hours: (a) RM, (b) PC, and (c) SC.

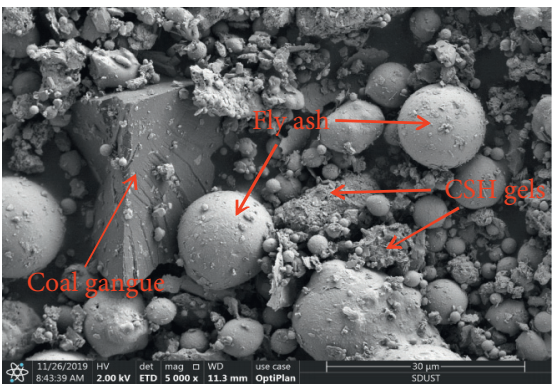

(a)

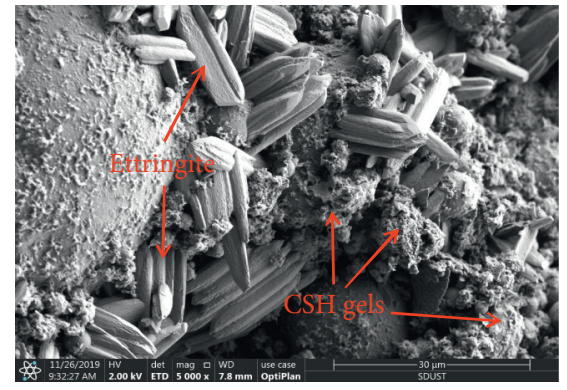

(b)

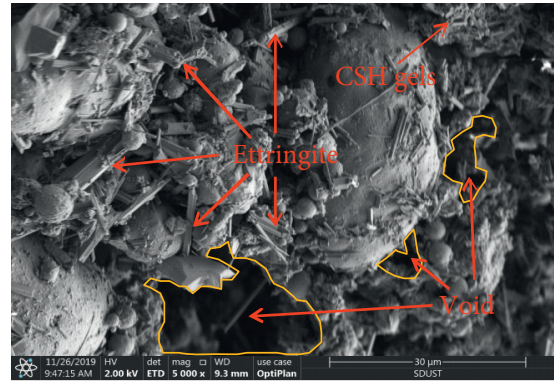

(c)

Figure 11: SEM images of CPB samples cured at $60^{\circ} \mathrm{C}$ for 12 hours: (a) RM, (b) PC, and (c) SC.

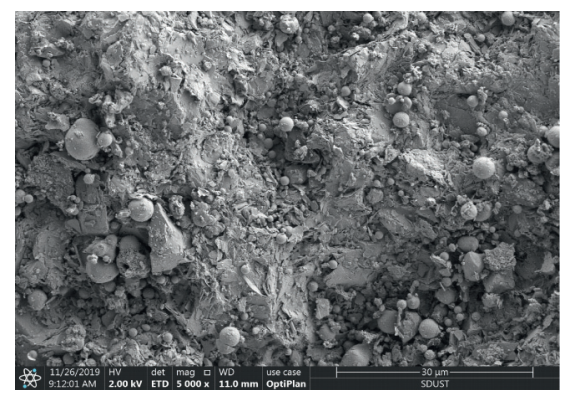

(a)

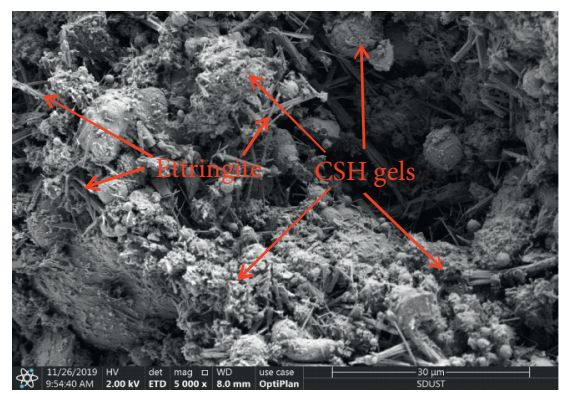

(b)

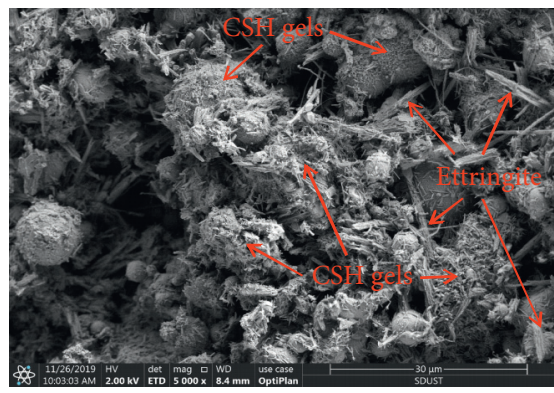

(c)

Figure 12: SEM images of different samples cured at $80^{\circ} \mathrm{C}$ for $12 \mathrm{~h}$ : (a) RM, (b) PC, and (c) SC.

diffraction peak of AFt decreases. SEM images show that the samples show obvious powdery damage after being cured for 12 hours at $80^{\circ} \mathrm{C}$. This is mainly because $80^{\circ} \mathrm{C}$ has exceeded the limit temperature of AFt. In other words, the structure of AFt was destroyed at $80^{\circ} \mathrm{C}$ [34].

The change of the UCS of the sample was closely related to the internal space of the sample, the volume of the crystal, the heat resistance of the crystal, and the hydration raw material provided by the binder. In other words, the UCS of the sample is an index that is affected by many factors. The coupled effect of binder type and temperature on UCS shows that $\mathrm{PC}$ and SC binders and temperatures $\left(20^{\circ} \mathrm{C}, 40^{\circ} \mathrm{C}\right.$, and $80^{\circ} \mathrm{C}$ ) seem to have positive effects. This discovery is of great significance for mining efficiency and improvement of backfill support. The stability variation of the CPB strength is particularly important for the design of mine filling. This is obviously related to the economic benefits of the mine, and the risk of failure can be reduced by mastering the matching point pair of stability.

In addition, we only studied the effect of medium and low temperature on the stability of $\mathrm{CPB}$. When the underground fire occurs, the $\mathrm{CPB}$ will be affected by high temperature. It is a new idea to study the stability of $\mathrm{CPB}$ near high temperature heat source.

\section{Conclusions}

The purpose of the study is to evaluate the effect of binder type and temperature on the microstructural evolution and macroscopic strength development of $\mathrm{CPB}$. The results 
provide some new evidence that can contribute to the understanding of the hardening process of CPB with different binder types, namely, RM, PC, and SC, at different temperatures $\left(20^{\circ} \mathrm{C}, 40^{\circ} \mathrm{C}, 60^{\circ} \mathrm{C}\right.$, and $\left.80^{\circ} \mathrm{C}\right)$. The following conclusions can be drawn from this work:

(1) It is demonstrated that temperature strongly affects the performance of CPB. The UCS values of the SC sample are greater than those of the PC sample; the latter in turn is greater than the RM sample. The UCS of samples mainly depends on whether the binder could provide more raw materials for hydration products. SC and PC can provide an increased number of hydration raw materials (C3A, C3S) for the sample and can produce more hydration products, such as C-S-H gel and AFt. These hydration products fill the inner space structure of the sample and thus improve the compactness and UCS of the sample.

(2) It is found that temperature has positive and negative effects on the UCS of samples. When the samples that contain SC and PC are cured at different temperatures for 12 hours, the UCS of the samples will increase at the beginning, then decrease, and finally increase as a function of temperature. When the curing temperature is $\leq 40^{\circ} \mathrm{C}$, the UCS of the sample is positively related to the temperature mainly because the increase of temperature can accelerate the hydration process of the binder. When the curing temperature is $60^{\circ} \mathrm{C}$, the UCS values of the samples decrease. The main reason is attributed to the fact that this temperature promotes the formation of more expansive AFt that has a larger bearing capacity than that of the internal space of the samples. When the curing temperature is $80^{\circ} \mathrm{C}$, the strengths of the samples that contain PC and SC increase again. The main reason is that the increased temperature damages the structure of $\mathrm{AFt}$ and promotes the hardening of the $\mathrm{C}-\mathrm{S}-\mathrm{H}$ gel. In addition, the UCS of the sample is closely related to the internal space of the sample, the volume of hydration products, the influence of temperature on the hydration products, and the hydration raw materials provided by the binder.

\section{Data Availability}

The data used to support the findings of this study are available from the corresponding author upon request.

\section{Conflicts of Interest}

The authors declare that there are no conflicts of interest regarding the publication of this paper.

\section{Acknowledgments}

This study was supported by the National Key R\&D Program of China (2018YFC0604704), the National Natural Science Foundation of China (51774194), the Shandong Provincial
Natural Science Fund for Distinguished Young Scholars (JQ201612), the Shandong Provincial Key R\&D Plan (2017GSF17112), the Shandong Provincial Natural Science Fund (ZR2018ZC0740), and the Taishan Scholars Project.

\section{References}

[1] W. Li and M. Fall, "Sulphate effect on the early age strength and self-desiccation of cemented paste backfill," Construction and Building Materials, vol. 106, pp. 296-304, 2016.

[2] L. Liu, Z. Fang, M. Wang, C. Qi, Y. Zhao, and C. Huan, "Experimental and numerical study on rheological properties of ice-containing cement paste backfill slurry," Powder Technology, vol. 370, pp. 206-214, 2020.

[3] C. Qi and A. Fourie, "Cemented paste backfill for mineral tailings management: review and future perspectives," Minerals Engineering, vol. 144, Article ID 106025, 2019.

[4] L. Liu, J. Xin, C. Huan, C. Qi, W. Zhou, and K.-I. Song, "Pore and strength characteristics of cemented paste backfill using sulphide tailings: effect of sulphur content," Construction and Building Materials, vol. 237, Article ID 117452, 2020.

[5] Q. Sun, S. Tian, Q. Sun et al., "Preparation and microstructure of fly ash geopolymer paste backfill material," Journal of Cleaner Production, vol. 225, pp. 376-390, 2019.

[6] W. Xu, M. Tian, and Q. Li, "Time-dependent rheological properties and mechanical performance of fresh cemented tailings backfill containing flocculants," Minerals Engineering, vol. 145, Article ID 106064, 2020.

[7] S. Chen, Z. Du, Z. Zhang, D. Yin, F. Feng, and J. Ma, "Effects of red mud additions on gangue-cemented paste backfill properties," Powder Technology, vol. 367, pp. 833-840, 2020.

[8] M. Fall and M. Pokharel, "Coupled effects of sulphate and temperature on the strength development of cemented tailings backfills: Portland cement-paste backfill," Cement and Concrete Composites, vol. 32, no. 10, pp. 819-828, 2010.

[9] A. Wu, Y. Wang, H. Wang, S. Yin, and X. Miao, "Coupled effects of cement type and water quality on the properties of cemented paste backfill," International Journal of Mineral Processing, vol. 143, pp. 65-71, 2015.

[10] B. Ercikdi, A. Kesimal, F. Cihangir, H. Deveci, and İ. Alp, "Cemented paste backfill of sulphide-rich tailings: importance of binder type and dosage," Cement and Concrete Composites, vol. 31, no. 4, pp. 268-274, 2009.

[11] Q. Sun, T. Li, and B. Liang, "Preparation of a new type of cemented paste backfill with an alkali-activated silica fume and slag composite binder," Materials, vol. 13, no. 2, p. 372, 2020.

[12] W. Xu, P. Cao, and M. Tian, "Strength development and microstructure evolution of cemented tailings backfill containing different binder types and contents," Minerals, vol. 8, no. 4 , p. 167, 2018.

[13] E. Yilmaz, T. Belem, B. Bussière, M. Mbonimpa, and M. Benzaazoua, "Curing time effect on consolidation behaviour of cemented paste backfill containing different cement types and contents," Construction and Building Materials, vol. 75, pp. 99-111, 2015.

[14] K. Fang and M. Fall, "Effects of curing temperature on shear behaviour of cemented paste backfill-rock interface," International Journal of Rock Mechanics and Mining Sciences, vol. 112, pp. 184-192, 2018.

[15] W. Xu, Q. Li, and B. Liu, "Coupled effect of curing temperature and age on compressive behavior, microstructure and ultrasonic properties of cemented tailings backfill," 
Construction and Building Materials, vol. 237, Article ID 117738, 2020.

[16] S. Chen, Z. Du, Z. Zhang, H. Zhang, Z. Xia, and F. Feng, "Effects of chloride on the early mechanical properties and microstructure of gangue-cemented paste backfill," Construction and Building Materials, vol. 235, Article ID 117504, 2020.

[17] X. G. Zhang, J. Lin, J. X. Liu et al., "Investigation of hydraulicmechanical properties of paste backfill containing coal gangue-fly ash and its application in an underground coal mine," Energies, vol. 10, pp. 1-19, 2017.

[18] W. Mu, L. Li, T. Yang, G. Yu, and Y. Han, "Numerical investigation on a grouting mechanism with slurry-rock coupling and shear displacement in a single rough fracture," Bulletin of Engineering Geology and the Environment, vol. 78, no. 8, p. 6159, 2019.

[19] O. H. Wallevik and J. E. Wallevik, "Rheology as a tool in concrete science: the use of rheographs and workability boxes," Cement and Concrete Research, vol. 41, no. 12, pp. 1279-1288, 2011.

[20] ASTM C 143, Standard Test Method for Slump of Hydraulic Cement Concrete, ASTM International, West Conshohocken, PA, USA, 2008.

[21] W. Xu, M. Han, and P. Li, "Influence of freeze-thaw cycles on mechanical responses of cemented paste tailings in surface storage," International Journal of Mining, Reclamation and Environment, vol. 34, no. 5, pp. 326-342, 2020.

[22] J. Zhao, L. Yin, and W. Guo, "Stress-seepage coupling of cataclastic rock masses based on digital image technologies," Rock Mechanics and Rock Engineering, vol. 51, no. 8, pp. 2355-2372, 2018.

[23] Y. Guo, P. Wang, G. Feng, T. Qi, G. Liu, and A. Ren, "Performance of coal gangue-based cemented backfill material modified by water-reducing agents," Advances in Materials Science and Engineering, vol. 2020, Article ID 2302895, 11 pages, 2020.

[24] P. Ghoddousi and L. Adelzade Saadabadi, "Study on hydration products by electrical resistivity for self-compacting concrete with silica fume and metakaolin," Construction and Building Materials, vol. 154, pp. 219-228, 2017.

[25] T. Johanna, C. Andrzej, and P. Vesa, "Effects of mineral powders on hydration process and hydration products in normal strength concrete," Construction and Building $M a$ terials, vol. 72, pp. 7-14, 2014.

[26] X. Lu, S. Wang, Z. Ye, C. Li, and X. Cheng, "Study on the hydration product of ettringite in cement paste with ethanoldiisopropanolamine," Journal of Thermal Analysis and Calorimetry, vol. 139, no. 2, pp. 1007-1016, 2020.

[27] X. B. Min, D. G. Liu, L. Y. Chai et al., "Comparison of arsenic immobilization properties among calcium silicate hydrate, ettringite, and Friedel's salt in a slag-based binder," Environmental Progress \& Sustainable Energy, vol. 38, pp. 422-428, 2019.

[28] C. Qi, Q. Chen, A. Fourie, J. Zhao, and Q. Zhang, "Pressure drop in pipe flow of cemented paste backfill: experimental and modeling study," Powder Technology, vol. 333, pp. 9-18, 2018.

[29] N. Yoobanpot, P. Jamsawang, K. Krairan, P. Jongpradist, and S. Likitlersuang, "Laboratory investigation of the properties of cement fly ash gravel for use as a column-supported embankment," Construction and Building Materials, vol. 257, Article ID 119493, 2020.

[30] J. Zhao, X. Zhang, N. Jiang, L. Yin, and W. Guo, "Porosity zoning characteristics of fault floor under fluid-solid coupling," Bulletin of Engineering Geology and the Environment, vol. 79, no. 5, pp. 2529-2541, 2020.

[31] J. Zhao, J. Chen, X. Zhang, J. Ning, and Y. Zhang, "Distribution characteristics of floor pore water pressure based on similarity simulation experiments," Bulletin of Engineering Geology and the Environment, vol. 79, no. 9, p. 4805, 2020.

[32] X. Qiao and J. Chen, "Correlation of propagation rate of corrosive crack in concrete under sulfate attack and growth rate of delayed ettringite," Engineering Fracture Mechanics, vol. 209, pp. 333-343, 2019.

[33] J. Yu, J. Qian, J. Tang, Z. Ji, and Y. Fan, "Effect of ettringite seed crystals on the properties of calcium sulphoaluminate cement," Construction and Building Materials, vol. 207, pp. 249-257, 2019.

[34] F. Han, Y. Zhou, and Z. Zhang, "Effect of gypsum on the properties of composite binder containing high-volume slag and iron tailing powder," Construction and Building Materials, vol. 252, Article ID 119023, 2020. 